\title{
La vida de Buda en lengua castellana (1890-1920)
}

\author{
José Ricardo Chaves
}

En este ensayo se revisa la recepción inicial de la leyenda de Buda en lengua castellana, con base en autores del modernismo panhispánico, con sus diferentes perspectivas, a partir de la última década del siglo XIX hasta la aparición del libro de José Vasconcelos, Estudios indostánicos (1920), en que se buscó superar la imprecisión biográfica y cultural dominante hasta entonces por medio de un discurso más académico y mejor informado.

Palabras Clave: budismo, modernismo hispanoamericano, leyenda de Buda.

In this essay, the author develops the early reception of the Buddha's legend in the Spanish language, beginning with writers classified as "Modernistas", from the last decade of the 19th century, to the book of José Vasconcelos Estudios indostánicos (Indostanic Studies) (1920), that tried to overcome the biographic and cultural faults of his predecessors by means of a more academic work.

KEYwords: Buddhism, hispanic Modernismo, Buddha’s legend. 

José Ricardo Chaves

Instituto de Investigaciones Filológicas

Universidad Nacional Autónoma de México

\section{La vida de Buda en lengua castellana (1890-1920)}

No siempre hubo Buda y budismo en el imaginario occidental, sino que tales nombres surgieron en tiempos modernos, sobre todo a partir del siglo XIX. La conformación de un cuerpo sistemático de discursos e imágenes sobre Buda y el budismo en castellano, esto es, traducido geográficamente, en España e Hispanoamérica, se inicia hacia la última década del siglo XIX ${ }^{1}$ y es inseparable de un proceso cultural mayor vinculado, más que con su recepción (como podría pensarse ingenuamente), con su construcción (por medio de conceptos, textos traducidos, imágenes) en el resto de Europa y en Estados Unidos. La generación del concepto "budismo" y de su personaje central, Sidarta Gautama, el Buda, se dio ahí de forma sistemática a partir del siglo XIX, en plena atmósfera romántica. Si bien hubo indicios de Buda y su doctrina antes (por ejemplo, en Marco Polo o en la leyenda cristiana del santo de la India, Barlaam y Josafat), no se había generado una visión más precisa de Buda (como comenzaría a hacerse con el romanticismo), sino que aparecía inmerso y a veces disuelto en el mundo mayor de la India y el hinduismo, del que sería quizás una desviación de la norma, apenas

${ }^{1}$ Hay antecedentes valiosos como el libro de viajes del mexicano Francisco Bulnes, Sobre el Hemisferio Norte once mil leguas. Impresiones de viaje a Cuba, los Estados Unidos, Japón, China, Cochinchina, Egipto y Europa, de 1875, que dedica todo un capítulo a Buda y al budismo. 
un avatar de Vishnú, su novena encarnación. En el bosque brumoso del orientalismo, no se lograba distinguir el árbol del budismo.

\section{Orientalismo romántico y teosófico}

Los románticos secretaron su propio orientalismo, una forma de exotismo vinculada, en el caso de la India, con la sabiduría y el éxtasis. El poeta y crítico Friedrich Schlegel escribió que había que buscar el supremo romanticismo en Oriente e hizo de la India la cuna de la religión. Después, se fue a estudiar sánscrito a París. Antes que él, Herder también había abordado las virtudes arquetípicas de la India, en tanto manifestación más cercana al origen, en vida y espiritualidad, en mito y poesía. Con ellos y muchos otros, el sánscrito pareció desplazar en virtudes mágicas al hebreo, hasta entonces la lengua reinante en misterio por sus vinculaciones cabalísticas y egipciacas. Los románticos amaron la búsqueda de los orígenes de muchas cosas: el ombligo del estado, del mito, de la poesía, del lenguaje, y en este sentido la antigüedad del sánscrito lo proyectaba más allá del hebreo, a las fuentes indoeuropeas, aspiración que más adelante cristalizaría en los sueños de opio de la raza aria.

Para el romántico, el mito entre más antiguo, mejor; más cerca está de la fuente, de la verdad. De sus distintas versiones, la más lejana es la más cierta. El fantasma del origen y la ilusión de causalidad están ahí vigentes, como ya lo señalara Nietzsche, como lo propio del pensar positivo. Nada más contrario a este proceder retroactivo, siempre hacia atrás, que la respuesta estructuralista de Lévi-Strauss en el siguiente siglo, en la que todas las versiones del mito cuentan igual y entre todas ayudan a conformar su patrón básico.

En la Europa del XIX, los principales países que debatieron sobre budismo y que produjeron incluso instancias académicas de erudición, traducción y comentario, fueron Francia, Alemania e Inglaterra. Esta última llegaría a dominar en este ámbito académico en parte por sus intereses coloniales directos. Este aspecto de alta cultura estuvo acompañado de una proyección más popular, canalizada por la prensa y el orientalismo pictórico y decorativo. En el caso de España no se dio un 
orientalismo académico comparable al de Francia o Inglaterra y en Hispanoamérica de plano no se dio hasta mucho después. En estos últimos casos lo que se produjo fue sobre todo un orientalismo de segunda mano, importado, cuando menos en lo que a la India respecta, que se ponía al tanto del asunto leyendo a los sabios franceses, ingleses y alemanes y sus traducciones.

Un factor muy importante de popularización budista, sin importar qué tan acertada fuera su presentación, fue la teosofía, una corriente pararreligiosa de tipo ocultista surgida a mediados de los setenta del XIX, que en su planteamiento sincrético daba a Buda y al budismo un lugar central, como la religión exotérica más cercana a la fuente primordial de las religiones históricas. De hecho, todavía hasta no hace mucho tiempo casi se hacían sinónimos budismo y teosofía, por supuesto, de forma equivocada, pues el primero es asiático y milenario, y la segunda, europea y decimonona.

La amplitud cultural de la teosofía atrajo a mucha gente, incluidos notables intelectuales y artistas, que sirvieron de enlace entre las altas obras académicas y un budismo más accesible que no descartó la expresión literaria. Como movimiento intelectual y religioso, la teosofía fue exitosa en toda América, Europa y algunos países asiáticos como la India. En el mundo hispánico, la teosofía se expandió rápidamente a ambos lados del Atlántico y para principios de siglo xx ya estaban traducidas al español las principales obras teosóficas, las de Madame Blavatsky, primero, y muy pronto las de Besant y Leadbeater, sus neoteósofos continuadores. Hubo toda una red de publicaciones regionales, en la que destacó la revista Sophia, de España, que se leyó también más allá de sus fronteras, del otro lado del mar. En sus páginas pueden encontrarse referencias a Buda y el budismo, así como notas sobre traducciones de textos budistas al francés y al alemán. Los teósofos españoles conformaron toda una notable escuela de traductores, no solo de obras doctrinales, sino también literarias. Entre los más reconocidos están José Roviralta Borrell (el Fausto de Goethe, y la Bhagavad Gita), Federico Climent Terrer (la versión de Besant de la Bhagavad Gita), Edmundo González Blanco (Emerson, Carlyle, Ruskin) y, para nuestro tema dhármico, Rafael Urbano, quien en 1908 publicó su traducción de un clásico budista, el Dhammapada, en la Biblioteca Orientalista de 
Ramón Maynadé, en Barcelona. Después traducirá a Nietzsche. De esta manera, Buda y Nietzsche entraron al castellano por el mismo traductor.

\section{Best sellers budistas de fin de siglo XIX. Leyenda y doctrina}

Hubo a finales de siglo XIX tres libros sobre Buda y budismo de amplia resonancia internacional, verdaderos best sellers traducidos a múltiples lenguas del inglés. En primer lugar, The Light of Asia (La luz de Asia), quizá la obra literaria de mayor impacto en Occidente (hasta que apreció Siddharta, de H. Hesse) sobre la vida y la enseñanza del Buda (que en Hesse es tangencial), escrita la primera por el poeta victoriano Edwin Arnold en 1879, y que sería llevada al cine en 1925 en una coproducción de Alemania y la India, sin demasiado brillo en su versión de cine mudo, agotado quizá el impulso victoriano del poema de Arnold. En cambio, el Siddharta de Hesse se había publicado tres años antes, en 1922, y comenzaba a llenar las expectativas de nuevas generaciones de lectores interesados en el asunto orientalista.

El segundo libro de gran difusión del Dharma fue el Catecismo budista (1881), de Henry Olcott, norteamericano, fundador con Madame Blavatsky de la Sociedad Teosófica en 1875 en Nueva York, uno de los primeros conversos occidentales y reorganizador del budismo surasiático, al que inoculó formas protestantes de educación y divulgación. Es un texto organizado en forma de preguntas y respuestas, de carácter doctrinal, con un alcance quizá más limitado a algunos países asiáticos como la India y Ceilán, y a ámbitos teosóficos internacionales.

El tercer libro importante fue El evangelio de Buda (1894), del alemán radicado en los Estados Unidos Paul Carus, vertido al español por el ya mencionado traductor teosófico Rafael Urbano, y que buscó mostrar un budismo claramente diferenciado de sus presentaciones ocultistas. Trazas y citas de este libro pueden encontrarse en escritores de la época, como por ejemplo Amado Nervo en su libro El estanque de los lotos, publicado el año de su muerte, 1919.

Estos libros, sobre todo los de Arnold y Carus, aparte de los múltiples artículos en revistas y otras publicaciones, brindaron a los lectores no especializados de fines del XIX y principios del Xx los elementos bá- 
sicos del personaje de Sidarta Gautama, no tanto de sus doctrinas, sino de su leyenda, mismos que los escritores de entonces tuvieron a su disposición para embarcarse en sus propias versiones, junto con las fuentes académicas y eruditas que podían consultar.

Entre los asuntos que atrajeron la atención de los occidentales respecto al recién "descubierto" budismo dos son los más importantes: primero, su sistema ético, tan admirable según la visión cristiana desde el punto de vista de la compasión y el beneficio del otro, y tan diferente al mismo tiempo en la forma de explicar los fundamentos de tan noble acción (teísmo cristiano versus ateísmo budista).

El segundo asunto de mucho interés es el relativo a la leyenda del Buda, a su biografía maravillosa y ejemplar, confrontada a veces con la de Cristo, de mayor sesgo dramático, que parece culminar en su impactante crucifixión, cuando falta todavía lo mejor: su resurrección. Sin embargo, Buda gana en fineza filosófica, en comprensión desnuda de la realidad o de lo que suponemos como tal. El conflicto del Buda es ante todo consigo mismo, con la ley de su padre el rey. De manera opuesta, esta no es transgredida o puesta en duda por Jesús, cuyo mérito es justamente seguir la voluntad de su padre celestial.

Si bien la leyenda y la ética búdicas atrajeron la mirada occidental, otros aspectos escandalizaron: su ya mencionado ateísmo, que en estricto sentido debería llamarse más bien como simple no teísmo, Dios como una hipótesis prescindible para un vivir ético y sabio en el mundo; en todo caso, dicen los budistas, habría dioses, no Dios; también se rechazó la noción de karma, que se asimiló a destino y fatalidad, a lo escrito de antemano, verdadero escándalo para la mentalidad defensora del individuo (considerado arquitecto de su propio destino), base de la nueva civilización, moderna y capitalista. En este mismo sentido, junto al karma también fueron cuestionadas nociones antiyoicas como las de reencarnación y nirvana (entendido como disolución del yo en un océano trascendente).

Se van acuñando en español algunos neologismos que ingresaron al flujo cotidiano de los discursos como karma y nirvana, que al mismo tiempo se imponían en otras lenguas, y que se consagran cuando circulan más allá de lo periodístico o académico y acceden a la expresión poética. En especial nirvana recibirá una buena acogida en el mundo 
literario, que lo usará como metáfora de extinción y de muerte, más que de paz o de liberación. Sobre tal término traigo a colación las palabras de Borges:

Afirmar que la fascinación ejercida por el budismo sobre las mentes y las imaginaciones occidentales procede de la palabra nirvana es una exageración evidente que encierra una partícula de verdad. Parece imposible, en efecto, que esa palabra tan sonora y tan enigmática no incluya algo precioso. Los literatos europeos y americanos la han prodigado raras veces en la acepción originaria; bástenos recordar a Lugones, que la usa para significar la apatía o la confusión (Qué es el budismo, 84).

Podría agregarse al ejemplo de Lugones el del poeta uruguayo Julio Herrera y Reissig (1875-1910), quien vincula el nirvana con la disolución personal por medio de la droga en su narración Aguas del Aqueronte, cuyo solo título nos induce, de manera paradójica, a recordar el olvido por medio del río del mito griego cuyas aguas bebidas inducían la amnesia a las almas para iniciar otra vida. La vida se renueva con el olvido, parece ser la lección.

Canónicamente, del lado budista, la vida del Buda se suele representar en doce acciones o momentos, que incluso suelen pintarse en murales en los templos. Estas doce partes a veces están muy seguidas entre sí, se suceden muy rápidamente (como en las tres primeras), o a veces hay una gran distancia de tiempo (como entre la diez y la doce). Estos doce eslabones biográficos son: primero, la existencia del futuro Buda en el cielo Tushita, limítrofe entre el mundo superior de los dioses y el reino sin forma. Se trata, claro, de una existencia preterrenal. Segundo: su descenso del reino divino de Tushita al humano. Tercero: su entrada en el vientre de su madre, la reina Maya, la bella ilusión, anunciado por un sueño profético de ser invadida por un elefante blanco. Cuarto: su nacimiento indoloro, inmediatamente tras el cual el bebé camina y de cada una de sus huellas nace un loto. Quinto: su maestría natural en toda suerte de artes mundanas, desde el arco y la flecha hasta el debate intelectual. Sexto: su cómoda vida en palacio, llena de ocio y placer, de voluptuosa feminización. Séptimo: su partida de tan magnífico hábitat tras su encuentro con la vejez, la enfermedad y la muerte. Octavo: su 
subsiguiente práctica ascética, que lo lleva al borde de la aniquilación, cuando el yogui se vuelve calavera. Noveno: la victoria sobre Mara, diabólico señor de toda suerte de ilusiones mundanas y trascendentes. Décimo: la iluminación o, mejor, el despertar, salir del sueño cotidiano a la vigilia perpetua, la actualización de una condición innata de luz y vacío, la budificación. Número once: la enseñanza y codificación oral de la experiencia liberadora para beneficio humano y cósmico, la puesta en movimiento de la Rueda del Dharma. Por último, la duodécima: el parinirvana: la muerte física de Buda, la continuidad subjetiva de una manera impensable desde la objetividad, al ubicarse más allá de la palabra y de la percepción.

Como veremos, buena parte de las elaboraciones literarias de Buda dejarán de lado los aspectos milagrosos y fantásticos de su leyenda (por ejemplo, su existencia preterrenal en el cielo de Tushita presentada en los dos primeros eventos canónicos), siguiendo en esto la actitud de los eruditos budólogos de la época, ansiosos como estaban por dar un fundamento histórico y textual al Buda, sin atender demasiado al milagro y la maravilla.

\section{El Buda decadente de Blasco Ibáñez}

En las zonas hispanohablantes también se generó un Buda literario, igual que ocurría en inglés alrededor de Arnold, aunque sin su éxito de lectores, tal como puede apreciarse en varios escritos, siendo el más logrado desde un punto de vista narrativo uno del español Vicente Blasco Ibáñez (1867-1928), para asombro de algunos, dada su fama de escritor realista. Se trata de una obra de juventud, de 1896, una novela corta de tema orientalista, la vida del Buda descrita con lenguaje modernista, con cierta voluptuosidad decadente, que se complace en la descripción sensual de los cuerpos, tanto de las bailarinas y concubinas como del propio Buda, que queda erotizado, por ejemplo cuando debe realizar sus proezas físicas:

Sidarta se despojó de su turbante, pero cual la nieve, deslizóse el sayo de oro, que brillaba con reflejos de sol; se arrancó con gallardía el collar 
de perlas y los innumerables aros preciosos que resguardaban sus brazos y piernas, y quedó sin otra vestidura que el blanco ceñidor anudado sobre los riñones. Su desnudez provocó un murmullo de admiración. Las hermosas damas se deleitaron contemplando este cuerpo esbelto y gallardo como el de Rama, fuerte y musculoso, sin rudas protuberancias que alterasen la suavidad de la piel: un cuerpo que parecía emanar luz como de los dioses cuando se aparecen por la noche a los santos solitarios sumidos en la meditación (Obras completas, 890, tomo III).

Mayor empeño lingüístico hará Blasco Ibáñez para dotar a sus descripciones de bailarinas, bayaderas y acróbatas con un contenido sensual, con lo que el énfasis literario es más sobre el placer que sobre el dolor, lo cual, supongo, habría sido lo propio para señalar el interés budista: el sufrimiento y su extinción. Es más bien el hedonismo finisecular (no exento de pesimismo) el que campea en sus páginas, quizá como sublimación a las condiciones carcelarias que padecía el autor al escribirlas, tal como señala en su prólogo de 1927, cuando junta esa novela corta con otras tres bajo el título de Novelas de amor y de muerte.

Tras una descripción viril suntuosa, el Buda de Blasco Ibáñez sufre luego, mientras vive en palacio con su esposa y las mujeres de su harén, un proceso de feminización. El lujo, la comodidad, la belleza, la abundancia, el placer, todo esto afemina progresivamente a Sidarta en palacio, que todavía no es Buda pues no se ha iluminado tras bregar con la muerte, la enfermedad y la ascesis. La iluminación lo revirilizará en cierta forma, aunque muy pronto lo deshumanice al tornarlo cósmico. La escala de lo humano se disuelve en la condición búdica. A Blasco Ibáñez no le interesan los aspectos doctrinales de su personaje (incluso parece ignorarlos en ciertos momentos) sino sus posibilidades literarias; es, pues, la leyenda la que lo atrae, para darle su propia interpretación, no su filosofía ni su ética, que apenas aparecen al fondo, desdibujadas.

\section{Juan Valera y su paradójico rechazo de Buda}

En la misma España hay otro escritor interesado en Buda. Se trata de Juan Valera (1824-1905), quien ya desde la publicación de sus Leyendas 
del Antiguo Oriente se había propuesto desarrollar los asuntos orientalistas en la literatura de su país. Así lo dice en el prólogo:

Otra razón nos impulsa también a escribir estas leyendas. Deseamos divulgar un poco la literatura oriental antigua y empezar a emplearla en nuestra moderna literatura española. En Francia y en Inglaterra y en Alemania, el renacimiento oriental $[\ldots]$ deja tiempo ha sentir su influjo en el arte y en la poesía. En España aun no se nota nada de esto (Obras completas, 901).

En su última novela, Morsamor, Valera cambia radicalmente el registro narrativo empleado hasta entonces y apuesta por una novela de asunto fantástico, solo que ambientada históricamente en el siglo XVI, con lo que vuelve menos claro su propósito de dar rienda controlada a su fantasía. La suya es una novela del esplendor imperial de España y Portugal, fantasía compensatoria del derrumbe del imperio realmente existente, mostrada en las peripecias de su personaje fáustico que rejuvenece alquímicamente y viaja por el mundo, incluida la India y el Tíbet, donde tiene la oportunidad de estudiar directamente con los mismos maestros espirituales que, siglos después, dictarán a Madame Blavatsky su teosofía. El personaje de Valera, hereje pero cristiano, rechazará finalmente las enseñanzas tibetanas y se lanzará a las profundas aguas del quietismo místico, cercano al de Miguel de Molinos, cuya guía espiritual por esos mismos tiempos era puesta de nuevo en circulación por los propios teósofos españoles en su revista Sophia, en especial por Rafael Urbano, tras bastante tiempo de relativo olvido, opacada quizá por el brillo poético de santa Teresa y de san Juan de la Cruz, con misticismos menos disolventes.

Valera menciona al Buda más por su filosofía que por su leyenda. Menciona el asombro de los portugueses al encontrar en la India enseñanzas reminiscentes de la ética cristiana, que atribuyeron a las predicaciones del apóstol santo Tomás, que allá anduvo y murió. Sin embargo, a continuación el narrador aclara:

La verdad era que lo que creían los portugueses cristianismo viciado era la religión fundada por Sidarta, príncipe de los sakias de Kapilavastu, 
y predicada en Ceilán algunos siglos antes de Cristo. La moral de esta religión no podía ser más santa ni más hermosa, pero su metafísica era errónea y desconsoladora. En el amor y la compasión por el infeliz linaje humano, sin distinción de castas ni de jerarquías, estribaba aquella moral, pero no tenía un Dios misericordioso (Morsamor, 196-197).

El narrador cristiano se extiende en el ateísmo budista, en su nirvana conducente a la aniquilación, por lo que el rechazo final del personaje está presente en potencia desde su llegada a la India. Llama la atención esta actitud relativamente negativa de Valera con respecto al budismo histórico, teniendo en cuenta que buena parte de su conocimiento al respecto viene filtrado por la teosofía de Blavatsky, de la que estuvo cercano en sus últimos años, como queda demostrado en la novela Morsamor. Esto porque la visión de Blavatsky es muy probudista (aunque por razones que se considerarían erróneas desde la ortodoxia) y el resultado es un Valera recristianizado hacia la vertiente mística.

\section{El Buda teosófico de Fernández Güell}

Una visión positiva de este budismo de extracción teosófica y espiritista que se dio a principios del xx en el área hispanohablante es la representada por Rogelio Fernández Güell (1883-1918), escritor costarricense que dejó su patria por razones políticas para irse a España, donde vivió por un tiempo y se casó, y que luego abandonara con su familia para trasladarse a México. En tierra azteca gozó de la amistad y de la protección del diplomático Ignacio Mariscal y del presidente Francisco I. Madero, con quienes compartió idearios masónico y espiritista. De hecho, con la ayuda de Madero, Fernández Güell editó algunas publicaciones espiritistas, tanto revistas como libros. En esta línea, su libro más destacado fue Psiquis sin velo. Tratado de filosofía esotérica (1912), dedicado justamente a su benefactor Madero. Entre otros asuntos, en dicho libro Fernández Güell hace un repaso de las diferentes doctrinas religiosas a lo largo de la historia, con la idea muy teosófica de que, pese a sus diferencias, las distintas religiones enseñan básicamente las mismas verdades, como debe ser dado su origen común en una suerte de 
antigua religión original, que luego se adaptó en cada religión concreta a las variaciones culturales e históricas de los hombres, algo, por cierto, no tan alejado de lo que habían planteado algunos autores del neoplatonismo renacentista como Pico de la Mirandola y Ficino.

Esta idea renacentista y luego romántica de una metarreligión primordial y prehistórica fragmentada luego en religiones históricas concretas fue retomada literariamente con ojo romántico a fines del siglo XIX por el escritor francés Edouard Schuré (1841-1929) en su libro de gran éxito Los grandes iniciados (1889), traducido a múltiples idiomas y reeditado hasta la fecha, dada su riqueza literaria, no tanto su consistencia histórica y mitológica. Pues bien, Fernández Güell hace en su libro Psiquis sin velo una suerte de seguimiento de algunos fundadores religiosos en la línea del libro de Schuré (su idea es desembocar en la última revelación: el espiritismo de Allan Kardec), en el que incluye a Buda, del que hace un resumen de su leyenda y de su doctrina, apoyado parcialmente en los escritos del orientalista Max Müller. Tras exponer algunos rasgos biográficos y doctrinales de Buda, Fernández Güell concluye:

De aquella eminentísima figura han hecho la codicia de los unos y la ignorancia de los otros, un dios, atribuyéndole palabras y milagros contrarios a sus propias enseñanzas. Mas, restaurándole, por decirlo así, en su figura humana, Budha aparece circundado de legítima gloria, como digno precursor de Cristo. Budha habló de las vidas sucesivas y de muchos otros de los principios sobre que descansa el Espiritismo Moderno. Se le condena por su interpretación del Nirvana, creyéndose que él buscaba la libertad del alma en su extinción completa (Psiquis sin velo, 36-37).

Y continúa su discurso intentando mostrar el carácter no nihilista del pensamiento budista, que era uno de los tópicos de la interpretación occidental por entonces, desde Nietzsche hasta Valera, lo que lo muestra como un intérprete a contracorriente de su época.

\section{El Buda político de Martí}

No todas las recreaciones literarias de Buda apuntan a la renuncia del mundo y al discurso sublime. Tenemos el caso del escritor cubano José 
Martí (1853-1895) quien, en su revista editada en Nueva York, La Edad de Oro, publicó un largo texto titulado "Un paseo por la tierra de los anamitas", en el que en un cierto pasaje se describe una pagoda budista de Vietnam y se cuenta la historia de Buda "que no fue dios cuando vivió de veras, sino un príncipe bueno, tan fuerte de cuerpo que mano a mano echaba por tierra a leones jóvenes, y tan hermoso que lo quería como a su corazón el que lo veía una vez, y de tanto pensamiento que no podían los doctores discutir con él, porque de niño sabía más que los doctores más sabios y viejos" (La Edad de Oro, 207-208). El recuento de Martí está exento de todo rasgo maravilloso y hacia el final se extiende sobre los usos políticos y económicos que otros hacen de Buda, una vez que muere, tanto sus alumnos, que "empezaron a vivir de lo que la gente les daba porque les hablasen de las verdades de Buda", como el rey del lugar, "que vio que en el nombre de Buda había poder, porque la gente miraba todo lo de Buda como cosa del cielo, tan hermoso que no podía ser hombre el que vivió y habló así" (210).

Viendo posibilidades de mayor dominio, el rey une sus esfuerzos con algunos discípulos:

Mandó el rey juntar a los discípulos para que pusiesen en libros la historia y los sermones y los consejos de Buda; y puso a los discípulos a sueldo, para que el pueblo viese juntos el poder del rey y el del cielo, de donde creía el pueblo que había venido al mundo Buda (210).

Muy pronto incluso el rey invade otros países, con el pretexto de divulgar el budismo: "Hubo unos discípulos que hicieron lo que el rey quería, y salieron con el ejército del rey a quitarles a los países de los alrededores la libertad, con el pretexto de que les iban a enseñar las verdades de Buda, que habían venido del cielo" (210). Vemos, pues, el establecimiento de un clero aliado al poder político y militar, que manipula las enseñanzas de Buda para provecho propio. En su elaboración, Martí no está basándose en ejemplo histórico o legendario de la vida de Buda, sino que está proyectando sus temores socialistas por la unión del estado y el clero para manipular las creencias religiosas populares en su propio beneficio. Si Martí se hubiera tomado la molestia de recurrir a la crónica histórica para informarse mejor y no solo proyectar sus fantas- 
mas, se habría encontrado más bien un contraejemplo de lo planteado por él en el caso del rey Asoka (272-231 a. C.), famoso monarca convertido al budismo y atemperado por este en sus afanes de conquista. La tolerancia del budismo hacia otras religiones es un rasgo de su devenir histórico ampliamente reconocido y que lo distingue de los aguerridos monoteísmos, por lo que Borges ha dicho que "la tolerancia del budismo no es una debilidad, sino que pertenece a su índole misma" (Siete noches, 78).

Este rey de la versión de Martí me hace pensar en el rey de la historia contada por Marco Polo, el viajero renacentista, quien fue el primero en Occidente en dar cuenta de la leyenda de Buda, a quien él nombra "Sergamoni Borchan" por Sakiamuni Buda. En el cuento de Marco Polo, el rey es el papá de Buda y lo sobrevive (a diferencia del recuento tradicional, en el que Buda alcanza los 80 años y, para cuando muere, su padre ya hace tiempo que falleció):

Y cuando el hijo del rey murió, se lo llevaron al rey su padre, y cuando este vio muerta a su criatura, que amaba más que a su propio cuerpo, le entró una desazón y una pena difíciles de describir. Quiso hacer una imagen a su semejanza, toda de oro y piedras preciosas, y fue venerada por todos los súbditos y adorado como un dios (Viajes, 178).

Marco Polo, quien no deja de admirar a la figura de Sergamoni Borchan, de quien dice que "si hubiera sido cristiano hubiese sido un gran santo como nuestro señor Jesucristo", quiere explicar de esa manera el nacimiento de la idolatría búdica, la representación de lo sacro en lo material, por medio del dolor del padre que, al ser rey, impone sus deseos sobre el pueblo y hace de su hijo un dios que habita la piedra y el metal. No tiene las ambiciones políticas y militares del rey de Martí, pero sí el poder para imponer una religión sobre sus súbditos.

\section{El Buda filosófico de Vasconcelos}

A diferencia de Valera, Blasco Ibáñez o Martí, cuyas elaboraciones de Buda tienen que ver con una apropiación estética desde la teosofía, la 
sensualidad decadente o la política, para el mexicano José Vasconcelos Buda es un asunto de reflexión ética y filosófica, y para ello no bastan las referencias vagas y poco informadas, sino que se requiere de un proceso de lectura de fuentes académicas, dada la imposibilidad de conocer los textos en sus propias lenguas (sánscrito y pali). Comparte sus intereses orientalistas con algunos escritores del Ateneo. Tal como expone en la introducción de su libro de 1920, Estudios indostánicos:

El gusto por estos estudios, tan poco cultivados entre nosotros de manera ordenada, nació en nuestras juntas inolvidables de hace unos ocho años, cuando nos reuníamos Antonio Caso, Pedro Henríquez Ureña, Alfonso Reyes y yo, en nuestro México, para discurrir sobre todos los asuntos que afectan directamente al espíritu. Ninguna enseñanza nos dejaba satisfechos, y ninguna de las grandes cuestiones fundamentales dejó de interesarnos vivamente. Disgustados de nuestro medio y decepcionados de Europa, que atravesaba por ese período de corrupción materialista que precedió a la guerra, nos deleitábamos algunas veces con las páginas indostánicas, que leíamos con mezcla de asombro y de curiosidad confusa (88).

Este libro marca un parteaguas con todo ese budismo teosófico imperante, y busca más bien un acercamiento histórico e informado lo mejor posible. En las páginas ahí dedicadas al budismo Vasconcelos menciona fuentes primarias como el biográfico Lalita Vistara, las Jatakas o recuentos de vidas pasadas del propio Buda o las preguntas del rey Milinda, y secundarias como Max Müller, Paul Carus o las traducciones de la Pali Texts Society. Poco de esto se había visto antes entre los poetas modernistas.

Vasconcelos introduce un incipiente rigor en el acercamiento a los temas búdicos, más allá del exotismo literario y de la extravagancia religiosa. Además de la exposición de leyenda y doctrina, Vasconcelos no escapó al tópico tan recurrido en su momento de comparar a Buda con Cristo, de forma tal que el primero, pese a toda su sabiduría, desconoce la doctrina de la compasión y la misericordia. Según él, Buda profetizó como una restitución futura de su doctrina, tras tiempos de degeneración, a la figura del Buda Maitreya. El giro curioso que realiza Vasconcelos es identificar a Cristo con Maitreya, ese buda futuro 
de bondad profetizado por Sidarta Gautama cinco siglos antes. De esta forma, Cristo iguala y supera a Buda, la Luz del Mundo obscurece a la Luz de Asia.

Por supuesto, estas elaboraciones de Vasconcelos muestran claramente su desconocimiento del budismo Mahayana y del ideal del bodisatva, este buda que se niega al nirvana hasta que todos los seres sensibles hayan alcanzado la iluminación, por lo que dedica sus esfuerzos al bienestar ajeno. Claro que al nivel del bodisatva no hay ni propio ni ajeno, ni samsara ni nirvana, ni yo ni otro. Todo este otro budismo históricamente mayoritario, el de Tíbet, China, Japón, Corea, es desconocido o cuando menos no tomado en cuenta por Vasconcelos. Como otros comentaristas de su tiempo, el budismo que más le interesa es el del Canon Pali, puesto que se le considera más exacto por su relativa cercanía a Gautama, el buda histórico. Comparte la ilusión romántica y positivista de los orígenes, se encuentra preso de la cronología, desatento al sentido global y a la diferencia. Anclado en esta restricción canónica, su comprensión del budismo se ve reducida, constreñida al pequeño vehículo de su elección búdica.

No obstante limitaciones de este tipo, Vasconcelos establece un parteaguas entre el budismo de salón y de revista literaria, acompañado de hashish y hastío (ese "budismo de los elegantes que usan monóculo y tiran florete", al decir del poeta colombiano José Asunción Silva en su novela De sobremesa), y, por otro lado, el budismo vuelto objeto de estudio y de reflexión cultural de mayor aliento, como ocurrirá después, ya en pleno siglo xx, en el campo filosófico con Ortega y Gasset, de manera más bien tangencial, o en el literario con autores como Borges, Octavio Paz y Severo Sarduy, el primero más cercano en lo personal al Zen japonés, Paz a Nagarjuna y el tantrismo, y Sarduy al budismo tibetano.

Con Vasconcelos comienza otra etapa de reflexión sobre el budismo, mejor informada, enriquecida con la posibilidad de visitar los países budistas que la industria del turismo pone a disposición, o tener acceso a maestros directos traídos de Asia o entrenados allá con los cuales (in) formarse. El budismo en español de fines del siglo XIX y primeras dos décadas del xx fue sobre todo literario, estético, no tanto histórico ni académico, mucho menos religioso. Resulta entonces que, en castellano, el Buda nació literario y solo después se tornó objeto académico y 
religioso, sin perder su elaboración poética. Vale la pena registrar este proceso en su expresión literaria.

\section{REFERENCIAS}

Blasco IbáÑ̃ez, Vicente, Obras completas, tomo III, Madrid, Aguilar, 1964.

Borges, Jorge Luis, Siete noches, México, Fondo de Cultura Económica, 1982. Borges, Jorge Luis y Alicia Jurado, Qué es el budismo, Buenos Aires, Emecé, 1991.

Fernández Güell, Rogelio, Psiquis sin velo. Tratado de Filosofía Esotérica, México, Tipografía y Litografía de Müller Hnos, 1912.

Frankuin, J. Jeffrey, The Lotus and the Lion. Buddhism and the Bristish Empire, New York, Cornell University Press, 2008.

Gallud JARDiel, Enrique, La India en la literatura española, Madrid, Aldebarán, 1998.

LenorR, Frédéric, El budismo en Occidente, Barcelona, Seix Barral, 1999.

Marco Polo, Viajes, México, Espasa-Calpe Mexicana, 1993.

MARTí, José, La Edad de Oro, Guanajuato, La Rana, 1997.

VALERA, Juan, Obras completas I, Madrid, Aguilar, 1958.

VALERA, Juan, Obras completas III, Madrid, Aguilar, 1964.

ValerA, Juan, Morsamor, Leonardo Romero Tobar (ed.), Barcelona, Plaza \& Janés, 1984.

Vasconcelos, José, “Estudios indostánicos”, en Obras completas III, México, Libreros Mexicanos Unidos, 1959. 